\title{
Iniciativas turísticas, geografía humana y del transporte en asentamientos rurales en la zona Huetar Norte de Costa Rica: El caso de San Juan de Peñas Blancas, San José de la Tigra, El Futuro y Boca San Carlos
}

\author{
Adrián Ruiz Rodríguez ${ }^{1}$ \& Luis Daniel Vega Herrera ${ }^{2}$ \\ 1. Cátedra Políticas de Conservación, UNED. aruiz@uned.ac.cr \\ 2. CITTED, UNED. Ivegah@uned.ac.cr
}

Recibido: 00 noviembre 2012

Aceptado: 00 febrero 2013

\section{RESUMEN}

La Región Huetar Norte entre otras cosas se caracteriza por la actividad agropecuaria y turística. Estudiando características generales de asentamientos, se determinan limitaciones y necesidades para el desarrollo de un turismo acorde con su contexto, considerando superestructura, distancias, iniciativas y posibles atractivos. Destacan limitaciones educativas y operacionales; sin embargo ofertan alimentos, cultura agropecuaria y turismo rural. Este estudio y su proceso cabría dentro de la investigación- acción pues las etapas de diagnóstico participativo se han integrado con coordinación institucional, ejecución de capacitación y transferencia por parte de la Escuela de Ciencias Exactas y Naturales (ECEN: 2008- a la fecha) y la Escuela de Ciencias Sociales y Humanidades (ECSH: 2013).

Palabras clave: turismo, asentamientos rurales, campesinos.

\begin{abstract}
The North Huetar Region of Costa Rica is characterized -among other things- by its agricultural activities and tourism. By studying general characteristics of settlements, we determined limitations and needs for tourism development according to its context, considering superstructure, distances, and attractiveness of possible initiatives. It has important educational and operational limitations, but offers food, farming and a rural tourism culture. This study is an "immediate impact" initiative based on participatory assessment stages that integrated institutional coordination, implementation, training and transfer by the School of Natural Sciences (ECEN: 2008 - to date) and the School of Social Sciences and Humanities (ECSH: 2013) of the Costa Rican Distance Education University.
\end{abstract}

Key words: tourism, farming settlements, farmers.

\section{Objetivos del estudio}

Caracterizar los asentamientos campesinos aledaños al Centro de Investigación y Transferencia de Tecnología para el Desarrollo (CITTED-La Perla) para determinar sus condiciones de acceso, planta, organización y servicios.

Determinar las necesidades, oportunidades, servicios y desafíos para el desarrollo turístico en los asentamientos meta del estudio.

Identificar las áreas de acción potenciales de la UNED en la zona de estudio a partir de las condiciones de los asentamientos seleccionados.

\section{Síntesis de actividades y métodos}

El proyecto "Diagnóstico del potencial para el desarrollo turístico sostenible en asentamientos campesinos del área de influencia del CITTED”, fue iniciativa de la Cátedra Políticas de Conservación de la UNED desde 2008. Para 2009 a 2011 se articuló el trabajo con actividades de Fondos de Regionalización Interuniversitaria y desde 2010, se fortaleció el componente Turismo y Gestión Ambiental del CITTED, para lo que se otorgaron fondos propios de la Escuela de Ciencias Exactas y Naturales. En 2013 se coordinó con la Escuela de Ciencias Sociales y Humanidades, en especial con la carrera Gestión Turística Sostenible y a la fecha se mantiene una valiosa coordinación con el proyecto. 


\section{Tipo de estudio}

Como explicó en otro estudio Ruiz (2009), el proyecto tuvo un enfoque no experimental pues no hubo controles sobre las variables y describe situaciones y eventos para colaborar con la relación entre variables críticas. Ya que la intención es contribuir con el mejoramiento de capacidades e iniciativas mediante la acción universitaria, no hay control de las variables independientes y se dirige a describir situaciones de campo que determinen la información básica. El estudio podría contener elementos de investigación aplicada, en tanto el producto final signifique un insumo para la organización local, así como colaborar en la definición de pautas para la gestión del espacio en materia turística y un mayor beneficio del turismo en la economía local.

\section{Población objeto del estudio}

Los actores son los productores agropecuarios de los asentamientos campesinos en el área de influencia del CITTED que poseen iniciativas y capacidades vinculadas con la actividad turística. A ellos se les pretende contribuir con acciones específicas de implementación en el corto y mediano plazo, tal como acompañamiento técnico, capacitación y prueba de producto turístico, partiendo de la identificación de condiciones favorables y desfavorables.

Otro segmento de actores son personas físicas, jurídicas o institucionales que poseen recursos y potestades afines con los propósitos del estudio.

\section{Criterios de las unidades de estudio}

Las personas que se involucraron en el análisis debían ser residentes nacionales o extranjeros del área de estudio, con parcelas agrícolas en uso actual, con apoyo institucional local, organizados dentro de alguna modalidad de grupo social (asociación de desarrollo, ASADA, Cooperativa, otros) y con iniciativas o capacidades para participar en el sector turismo de forma directa o indirecta, en tanto deben estar dentro de los cantones aledaños al CITTED.

\section{Fuentes de información}

Como en estudios previos de Ruiz (2002; 2009), se utilizó información de fuentes primarias y secundarias. La primera colectada por medio de cuestionarios estructurados y no estructurados, observación participante y no participante y registros de campo. La primaria fue proporcionada por las personas durante las consultas, así como los informes sobre estudio en el sitio que se obtuvo con trabajos académicos y brindada por los autores (Ángeles et al, 2006). En la misma categoría de información cabe la colectada por los autores con el trabajo de campo mediante registro fotográfico, toma de notas y observaciones.

Respecto a la información secundaria, provino de la revisión documental producida antes y después del desarrollo del estudio, tales como informes, documentos y otras investigaciones elaboradas. Se obtuvo de las fuentes ya publicadas y consultadas que no son proporcionadas directamente por los autores, tales como publicaciones electrónicas, artículos, estudios del tema o afines, tesis y toda aquella disponible al público en centros de información.

- 1 etapa (2008-2009): Estudio preliminar del área de estudio: consulta a las principales fuentes de información disponibles previo al trabajo de campo.

- 2 etapa (2009-2010): Visitas de prospección para identificación de oportunidades y desafíos: uso de guías de observación y capacitación en temas prioritario (senderos, conducción de grupos, calidad turística, entre otros).

- 3 etapa (2011-2012): Mapeo de rutas y atractivos con su registro en sistemas de información geográfica y diseño de propuestas de productos turísticos o capacitación local.

- 4 etapa (2011-2012): Consulta a los beneficiarios del proyecto: aplicación de cuestionarios, charlas y talleres en coordinación con otras institucionales locales (SINACACAHN, IDA- Clubes 4S, Bosque Eterno de los Niños, Finca Luna Nueva Lodge). 
- 5 etapa (2012-2013): Aplicación de actividades de seguimiento y acompañamiento de la ECSH.

Cabe destacar que la Cátedra Políticas de Conservación ha tenido como recargo el proyecto (8 horas quincenales) y el personal de apoyo salvo en 2012, ha sido recargado en otros proyectos e iniciativas de la ECEN en la Región.

\section{Instrumentos para colectar información}

La intención de utilizar guías de observación, observación participante, entrevistas no estructuradas y cuestionarios es complementar la información que se pueda producir, además de contar con la percepción del trabajador del negocio turístico como protagonista y población objeto.

Los datos colectados fueron:

- Áreas protegidas y proyectos turísticos en el área de estudio.

- Principales atractivos locales.

- Situación turística de La Fortuna.

- Ubicación de los asentamientos y cercanía con centros de población o atractivos locales.

- Iniciativas, limitaciones y atractivos potenciales de los asentamientos.

- Geografía humana local (organizaciones presentes, servicios públicos, acceso, y

- Necesidades de apoyo.

Para indagar en esos datos, se realizaron visitas de campo, en las que se hizo una prospección de las actividades económicas vinculadas con el turismo, información complementada con registro fotográfico. Posteriormente se aplicó una guía de observación para identificar y estimar la cantidad de negocios turísticos presentes y finalmente, se administraron cuestionarios dirigidos a los propietarios de esos negocios para caracterizar las condiciones de operación de la oferta. Es importante señalar que para efectos de la acción universitaria, se desarrollaron convocatorias a talleres, charlas y capacitaciones en los asentamientos y en las instalaciones del CITTED (Cuadro 20).

\section{Alcances del estudio}

\section{A. Proyecciones}

- Se espera desarrollar mapas de rutas turísticas y de ubicación de atractivos no convencionales complementarios en la región.

- Planificar acciones para desde la academia fomentar el mejoramiento de la calidad de vida de las poblaciones meta.

- Colaborar con las actividades de asistencia y capacitación de instituciones locales afines con el proyecto.

- Colaborar con los planes de desarrollo turístico rural en la Región.

\section{B. Limitaciones}

- Recursos escasos en las instituciones (transporte, viáticos, personal, carga académica).

- Recargo de la investigación y extensión docente a las tareas administrativas.

\section{Resultados}

\section{Breve caracterización de La Fortuna}

Aunque los destinatarios del proyecto son los productores de los asentamientos campesinos aledaños al CITTED, no se puede obviar la operación, imagen marca, influencia y trayectoria de La Fortuna.

Según el análisis de las diversas fuentes de promoción turística a nivel nacional e internacional, se encontró que La Fortuna es el principal centro turístico de la zona turística denominada Llanuras del Norte que forma parte de las estrategias nacionales del ICT contenidas en el Plan General de Desarrollo Turístico Sostenible 2002-2012.

En el área ambiental, la producción más amigable y limpia, la reforestación y el mantenimiento de la calidad y cantidad del agua son áreas prioritarias, en particular cuando son la base elemental del turismo, el agro y la ganadería.

Los siguientes son datos extraídos de Ruiz y Vega (2008) y de Ángeles. D et al (2006: com. pers). 
La Planta turística ofrece servicios de hospedaje para múltiples segmentos, como "bed and breakfast", hoteles de lujo, turismo joven, individual y familiar, entre otros. Respecto a atractivos, la base es principalmente la naturaleza, encontrando diversificación en el turismo, por ejemplo, aventura, ecológico, deportivo, en el agua y en el bosque, canoppy, pesca, windsurf y otras modalidades complementarias como agroturismo y turismo cultural.

La red de transportes enlaza la región con San José, Alajuela, Tilarán y Monteverde, además hay servicios de transporte por tierra, aire y ríos, así como en el Embalse Arenal. Lo que destaca es que los servicios de transporte son elementales para el funcionamiento productivo y económico de la zona, no obstante deben hacerse mejoras sustanciales en la infraestructura vinculada a esta red.

De la aplicación de guías de observación y toma de notas de campo, se encontró que del área de estudio, con énfasis en La Fortuna se tiene que sus establecimientos son diversificados en lo que corresponde a una oferta turística de mercado:

- Hospedaje,
- Alimentación,

- Excursiones in y ex situ,

- Venta de artesanías y recuerdos,

- Taxis,

- Alquiler de quintas o apartamentos,

- Alquiler de autos,

- Alquiler de caballos y bicicletas, entre otras.

En la zona hay efectos económicos importantes del turismo, tales como:

- Oferta de propiedades en venta,

- Aumento del costo de la vida,

- Incorporación de elementos foráneos a la cultura local (idiomas, costumbres),

- Uso de euro, dólar y colón en la mayor parte de establecimientos turísticos y comerciales,

- Llegada de residentes extranjeros,

- Mantenimiento constante de la superestructura,

- Incremento de la plusvalía de las fincas productivas,

- Transformación de las unidades productivas en zonas residenciales.

- Incremento del empleo turístico directo e indirecto,

- Aumento de la oferta educativa formal.

Cuadro 1

\section{Resumen de los principales atractivos en el área de estudio}

\begin{tabular}{|c|c|}
\hline $\begin{array}{l}\text { Atractivos vinculados con geografía física (Volcán } \\
\text { Arenal y zona de amortiguamiento) }\end{array}$ & Embalse del Arenal, Parque Nacional Volcán Arenal. \\
\hline Atractivos vinculados con la hidrografía & $\begin{array}{l}\text { Río Tabacón, Catarata la Fortuna, Río San Carlos, Catarata de } \\
\text { San Fernando, Catarata del Ángel. }\end{array}$ \\
\hline $\begin{array}{l}\text { Atractivos vinculados con la conservación de } \\
\text { ecosistemas, biodiversidad y matrices de bosque. }\end{array}$ & $\begin{array}{l}\text { Bosque Eterno de los Niños, Monteverde, Refugio de Vida } \\
\text { Silvestre Caño Negro, Parque Nacional Juan Castro Blanco. }\end{array}$ \\
\hline Atractivos vinculados con la tradición agropecuaria. & Arenal Vida campesina, Finca Educativa don Juan. \\
\hline
\end{tabular}

Fuente: Revisión bibliográfica y Toma de notas de campo (2010). 


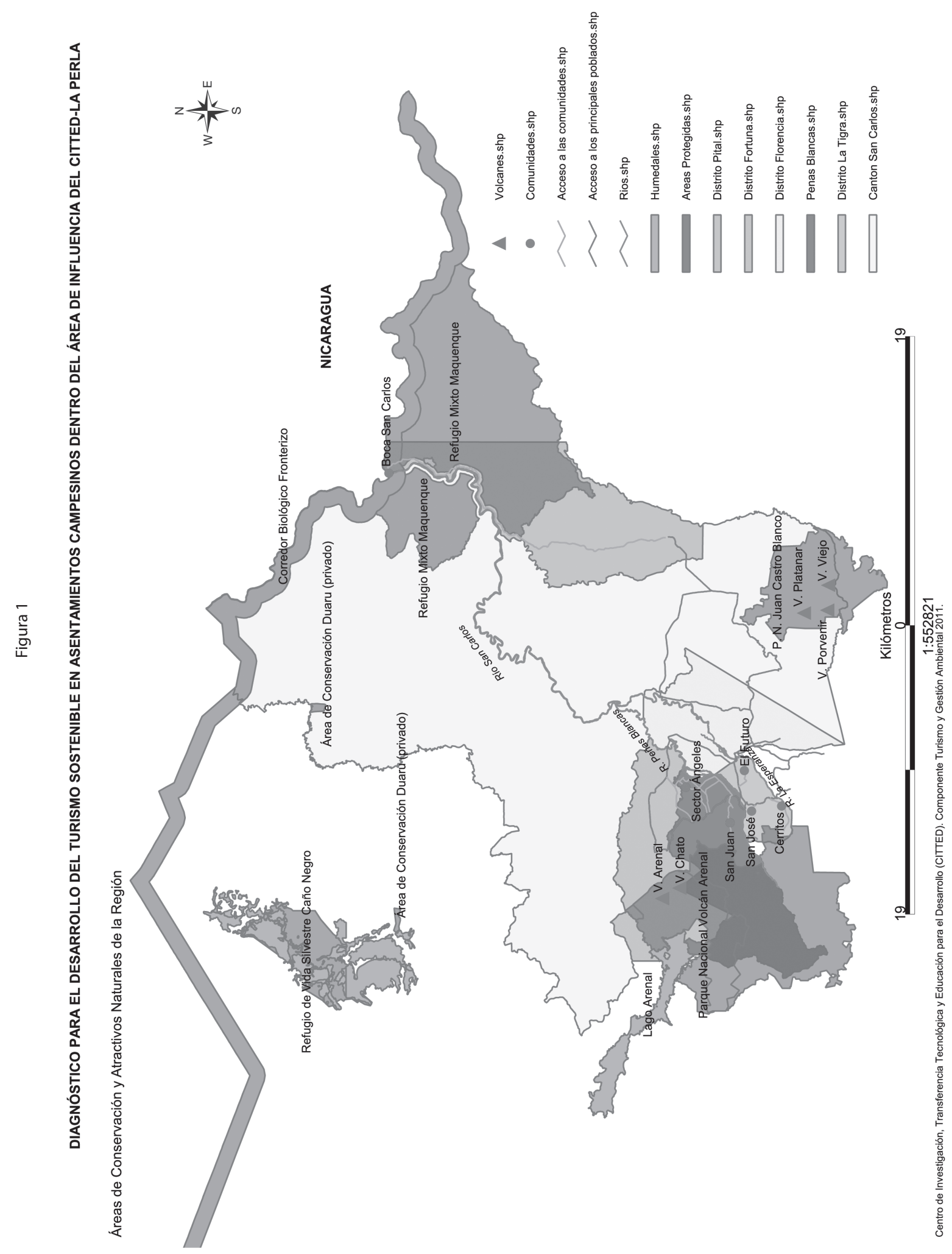




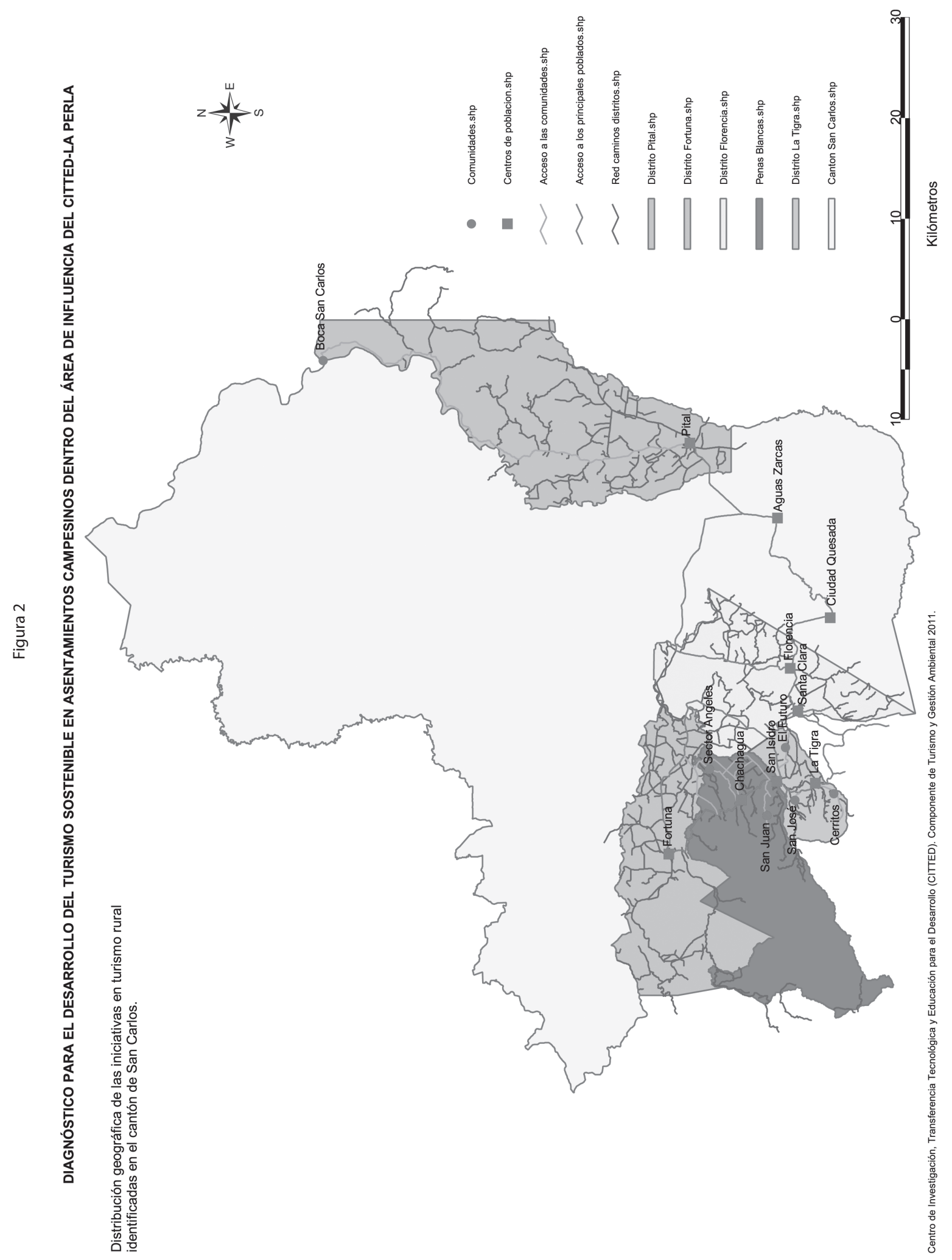


Cabe decir que muchos de los atractivos son de tenencia estatal y que a lo interno de las grandes instalaciones hoteleras se aprovechan recursos como aguas termales, zoocriaderos, senderos, cabalgatas, cultivos y artesanías; articulando el aprovechamiento de la tradición y cultura local.

\section{Situación de los asentamientos campesinos}

Inicialmente se consideró solo trabajar con los asentamientos más próximos al CITTED- La Perla que tuviesen intenciones o se encontraran trabajando en la economía turística, pero con la puesta en marcha de la metodología fueron apareciendo nuevos grupos interesados.

Los asentamientos presentan condiciones muy diferentes entren sí, por ejemplo, la cantidad de propietarios que los habitan, el tipo de organización que poseen, el tamaño del área de reserva, la tenencia de los terrenos en los que trabajan o pretenden trabajar o bien la percepción del tipo de servicio turístico con el que desean trabajar o han trabajado. También las distancias desde y hacia los principales centros de población, la planta de servicios públicos a los que tienen acceso y la redundancia vial.

Elementos comunes que poseen los productores de los asentamientos son el deseo de verse favorecidos económicamente del turismo en la zona, carencia de un atractivo focal y una planta turística aceptable dentro del entorno de la región, incertidumbre sobre la tenencia de las propiedades en las que desean trabajar, su tradición productiva y la educación no formal de algunos de sus miembros en torno a ramas complementarias al turismo o a su producción.

No hay claridad en cuanto al segmento de mercado al que se quieren dirigir, pero considerando que no dominan segundos ni terceros idiomas, que poseen poca capacidad de inversión, que su tradición es agropecuaria y que desean mejorar sus condiciones económicas y de vida complementándose con la actividad turística de La Fortuna, se les sugiere trabajar con visitantes y turistas nacionales.
Ventajas que poseen los asentamientos para poder iniciarse en la actividad turística, son:

- Cercanía a La Fortuna.

- Las áreas de reserva de bosque y sus recursos

- hídrológicos.

- El paisaje rural y productivo que distingue la rusticidad y tradición locales como potenciales a diversificar la oferta en La Región.

- Las tendencias nacionales para fomentar el turismo nacional y la modalidad de Turismo Rural Comunitario (TRC).

- La capacidad de complementar su tradición productiva con la proveeduría a otros negocios (tés, guías, alquiler de caballos, jabones, etc).

- La posibilidad de acceder a la mayor parte de asentamientos en transporte público, con vehículos livianos, bicicletas o tracción animal.

\section{Asentamiento El Futuro}

\section{Ubicación geográfica}

El asentamiento El Futuro está localizado en el distrito de La Tigra, cantón de San Carlos, provincia Alajuela.

Su ubicación permite acceder fácilmente a los principales centros poblacionales de la zona (ver figura 3).

\section{Cercanía con los atractivos turísticos más reconocidos}

Igualmente esta comunidad se encuentra relativamente cerca de los principales sitios de interés turístico de la región, los cuales, se citan en el siguiente cuadro (Cuadro 2).

\section{Organizaciones presentes en la comunidad}

Respecto a la organización comunal, El Futuro cuenta con un total de nueve comités, los cuales, responden a las diferentes necesidades de la comunidad. En el cuadro 3 se enlistan. 
CUADRO 2

Distancia entre la comunidad de El Futuro y los principales atractivos turísticos de la región

\begin{tabular}{|c|c|c|}
\hline Comunidades & Atractivos & Distancia en kilómetros \\
\hline \multirow[t]{5}{*}{ El futuro } & Lago Arenal & $42.16 \mathrm{~km}$. \\
\hline & Parque Arenal & $41.4 \mathrm{~km}$ \\
\hline & Cavernas de Venado & $51.4 \mathrm{~km}$. \\
\hline & Caño Negro & 135.18 km. \\
\hline & Estación Biológica Bosque Eterno de los Niños & $17 \mathrm{~km}$. \\
\hline
\end{tabular}

Fuente: elaboración propia basada en trabajo de campo, 2012.

CuAdRo 3

Organizaciones presentes en la comunidad del Futuro

\begin{tabular}{ll}
\multicolumn{1}{c}{ Comunidad } & \multicolumn{1}{c}{ Organizaciones } \\
Asentamiento El Futuro. & Asociación de Agricultores de El Futuro \\
& Asociación de Desarrollo Integral de El Futuro \\
& Asociación Administradora de Sistema de Agua Potable y Saneamiento (ASADA) El Futuro \\
& Sociedad de Usuarios de Agua (SUA) \\
& Consejo Económico (iglesia Católica) \\
& Patronato Escolar \\
Junta de Educación de El Futuro & Comité de Salud de El Futuro \\
Coopeornamentales R.L.
\end{tabular}

Fuente: Elaboración propia, 2008-2011.

Servicios de que dispone la comunidad: cantidad y ubicación

La comunidad cuenta con suficientes y bien distribuidos servicios básicos (ver cuadro 4), los cuales se detallan a continuación:

- El asentamiento cuenta con un acueducto exclusivo para la comunidad, dicho acueducto es administrado por una asociación administradora (ASADA). El 100\% de los pobladores tienen acceso al agua potable.

- La Electricidad es un servicio brindado por COOPELESCA R.L., la red de distribución cubre todas las áreas del asentamiento, que comprende un total de $14.94 \mathrm{~km}$.

- El asentamiento cuenta con servicio telefónico fijo, además de un teléfono público que

CUADRo 4

\section{Servicios presentes en la comunidad del Futuro}

\begin{tabular}{cll} 
Comunidad & \multicolumn{1}{c}{ Servicios Básicos presentes } & \multicolumn{1}{c}{ Proveedor } \\
Asentamiento El Futuro & Agua potable & ASADA EI Futuro \\
& Electricidad & COOPELESCA \\
& Telefonía fija & ICE \\
& Telefonía celular & ICE, Full Móvil, Tuyo Móvil, Movistar \\
& Internet & ICE, RACSA, COOPELESCA \\
& Educación preescolar y primaria. & Ministerio de Educación Pública (MEP) \\
& Salud (atención básica). & Caja Costarricense de Seguro Social (EBAIS La Tigra) \\
\hline
\end{tabular}

Fuente: Elaboración propia, 2008-2011. 


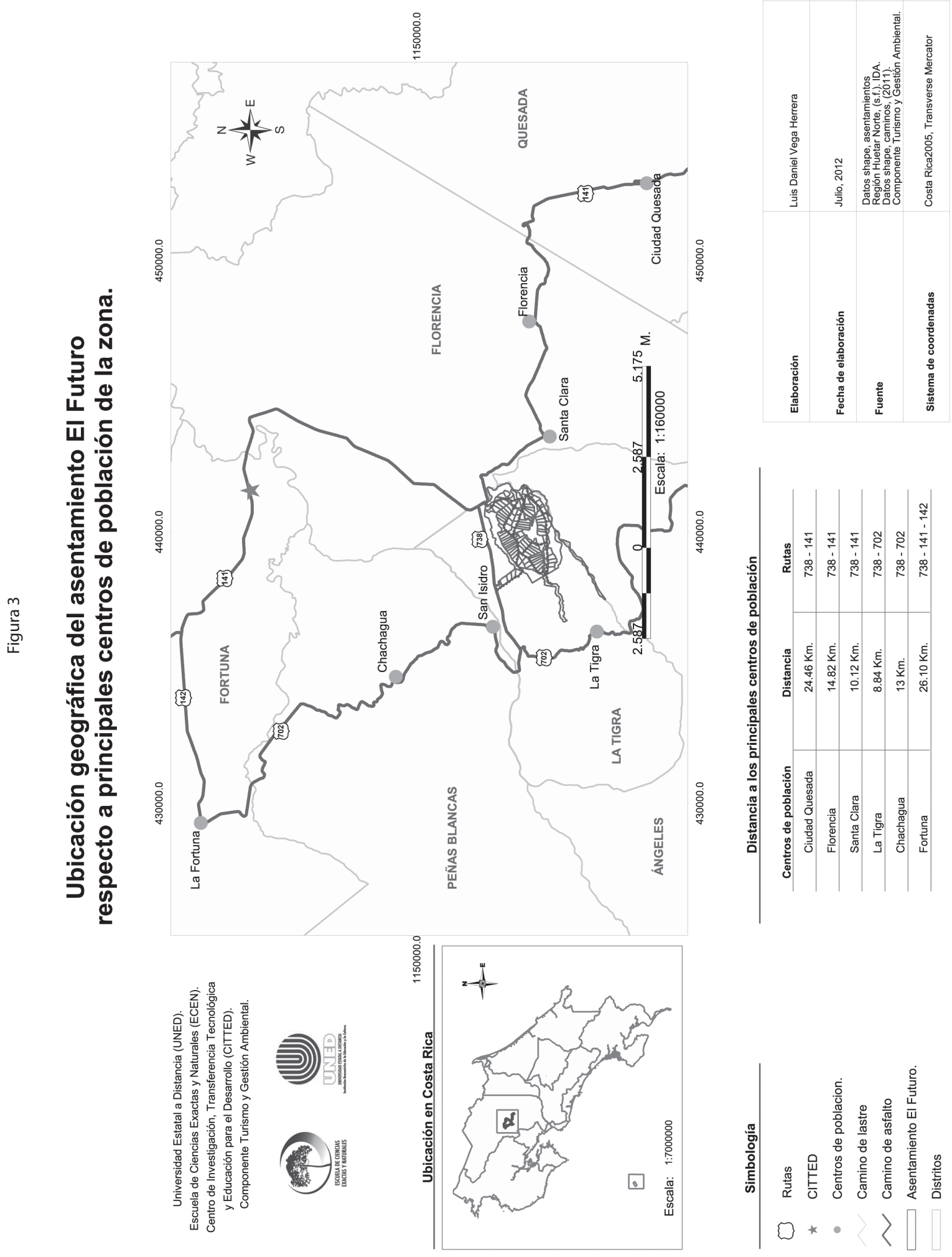


está ubicado en el centro comunal. En cuanto a la telefonía móvil, actualmente existen alrededor de cinco empresas que ofrecen el servicio.

\section{Acceso a la comunidad}

Las principales rutas de salida y entrada al asentamiento son:

- Ruta 702 que cubre de San Ramón - La Fortuna.

- Ruta 738 que cubre Javillos - La Tigra

- Ruta 739 que cubre San Ramón - Santa Clara - San Carlos.

Todas estas Rutas Nacionales, se mantienen en condiciones de regular a buenas, con pequeños trayectos a lo interno en mal estado.

A lo interno de la comunidad los caminos son de lastre en su totalidad, los cuales suman un total de $14.94 \mathrm{~km}$.

Iniciativas turísticas

\section{Asociación de Agricultores del Futuro}

La asociación de productores del asentamiento El Futuro plantea desarrollar un proyecto de turismo rural comunitario, a través del cual, puedan beneficiarse los afiliados de dicha organización.

Con este proyecto, la asociación pretende realizar un aprovechamiento de diferentes áreas con que cuenta el asentamiento, entre las cuales, destacan un antiguo beneficio de café, 230 ha de bosque maduro y un humedal de aproximadamente 5 ha., este último se encuentra en un proceso de regeneración natural.

\section{Atractivos presentes en la comunidad}

\section{Naturales}

El área que comprende el asentamiento cuenta con importantes zonas boscosas que presentan una gran diversidad de flora y fauna (ver cuadros 5 y 6). También el límite Sur del asentamiento está dado por el río la Esperanza, mientras que el límite Este está dado por el río San Carlos.

\section{Culturales}

Como atractivos culturales destacan principalmente la cotidianeidad de los pobladores, actividades productivas, fiestas populares y actividades religiosas (Cuadro 7).

\section{Necesidades de capacitación y apoyo técnico}

Como principales necesidades de capacitación fueron identificados los siguientes temas:

- Gastronomía.

- Flora regional.

- Fauna regional.

- Diseño de senderos.

- Calidad de los servicios turísticos.

- Contabilidad.

- Inglés.

- Atención al cliente.

- Manejo de residuos sólidos y aguas residuales.

La comunidad requiere principalmente de acompañamiento técnico en el campo de producción agrícola, manejo y recuperación del área de humedal, así como el manejo de las áreas de bosque, las cuales son consideradas como áreas de conservación.

\section{Observaciones}

Tienen problemas de invasiones a la reserva forestal por parte de parceleros que colindan con estas áreas, algunos no son afiliados a la organización.

Las áreas de reserva pertenecen al IDA; según miembros de la junta directiva de la asociación, esta situación les ha afectado para poder llevar a cabo la iniciativa turística que pretenden desarrollar.

En la comunidad se está gestionando el desarrollo de un proyecto hidroeléctrico en conjunto con Coopelesca, para el desarrollo de este proyecto, se captará el agua del río La Esperanza y Quebrada La Tigra, la cual será desviada a un 
CUADRO 5

Fauna terrestre representativa en las cuatro comunidades estudiadas.

\begin{tabular}{|c|c|c|c|}
\hline Clase & Hábitat & Nombre común & Nombre científico \\
\hline \multirow[t]{16}{*}{ Aves } & \multirow{15}{*}{$\begin{array}{l}\text { Más comunes en áreas abiertas, } \\
\text { zonas de cultivos y bordes de } \\
\text { montaña. }\end{array}$} & Oropendula montezuma & Psarocolius montezuma \\
\hline & & Piapia & Cyanocorax morio \\
\hline & & Chachalaca & Ortalis cinereiceps \\
\hline & & Pájaro chancho, titira carirroja. & Tityra semifasciata \\
\hline & & Sargento & Ramphocelus passerinii \\
\hline & & Viuda & Thraupis episcopus \\
\hline & & Pecho amarillo & Megarhynchus pitangua \\
\hline & & Pecho amarillo & Tyrannus melancholicus \\
\hline & & Pecho amarillo & Myiozetetes similis \\
\hline & & Yigüirro & Turdus grayi \\
\hline & & Platera & Tangara larvata \\
\hline & & Caracara & Caracara cheriway \\
\hline & & Gavilán bailarín & Elanus leucurus \\
\hline & & Guaco & Herpetotheres cachinnans \\
\hline & & gavilán & Buteo platypterus \\
\hline & $\begin{array}{l}\text { Observados principalmente en } \\
\text { áreas de bosque secundario, } \\
\text { bosque maduro, bordes de bosque } \\
\text { y zonas en regeneración. }\end{array}$ & Pastora & Trogon massena \\
\hline \multirow[t]{5}{*}{ Mammalia } & \multirow{5}{*}{$\begin{array}{l}\text { Observados en las áreas de bosque } \\
\text { bosque que se encuentran en } \\
\text { regeneración y áreas de cultivo. }\end{array}$} & Guatusa & Dasyprocta punctata \\
\hline & & Tolomuco & Eira barbara \\
\hline & & León breñero & Puma yaguarondi \\
\hline & & Armadillo o cusuco & Dasypus novemcinctus \\
\hline & & perezoso de dos dedos. & Choloepus hoffmanni \\
\hline \multirow[t]{9}{*}{ Reptilia } & \multirow{9}{*}{$\begin{array}{l}\text { Se puede observar en bordes de } \\
\text { bosque, áreas en regeneración } \\
\text { como el humedal y, en ocasiones, } \\
\text { en áreas cultivadas con poco } \\
\text { manejo. }\end{array}$} & Basilisco rayado o cherepo & Basiliscus vittatus \\
\hline & & Basilisco esmeralda & Basiliscus plumifrons \\
\hline & & Iguana verde & Iguana iguana \\
\hline & & Culebra bejuquillo cabezona & Imantodes cenchoa \\
\hline & & Ranera & Drymobius margaritiferus \\
\hline & & Bécquer & Boa constrictor \\
\hline & & Zopilota común; víbora de sangre & Clelia clelia \\
\hline & & Toboba de pestaña, bocaracá, oropel. & Bothriechis schlegelii \\
\hline & & Terciopelo & Botrops asper \\
\hline \multirow[t]{8}{*}{ Amphibia } & \multirow{3}{*}{$\begin{array}{l}\text { Observados en las áreas de } \\
\text { bosque y bordes de bosque }\end{array}$} & Ranita venenosa roja. & Oophaga pumilio \\
\hline & & Rana calzonuda & Agalychnis callidryas \\
\hline & & Rana & Scinax boulengeri \\
\hline & \multirow{5}{*}{$\begin{array}{l}\text { Se pueden encontrar viviendo cerca } \\
\text { de casas, áreas abiertas y zonas de } \\
\text { cultivo. También están presentes en } \\
\text { las áreas de bosque representativas } \\
\text { del lugar. }\end{array}$} & Rana & Smilisca phaeota \\
\hline & & Rana & Smilisca baudinii \\
\hline & & Sapo & Incilius melanochlorus \\
\hline & & Sapo & Rhaebo haematiticus \\
\hline & & Sapo & Rhinella marina \\
\hline
\end{tabular}

Fuente: INBio, 2011 


\section{Cuadro 6}

Especies forestales presentes en las cuatro comunidades estudiadas.

\begin{tabular}{|c|c|c|}
\hline Nombre común & Nombre científico & Hábitat \\
\hline Cristóbal & Platymiscium sp. & Encontrado en las áreas de reserva presentes en la comunidad. \\
\hline Gavilán & Pentaclethra macroloba & $\begin{array}{l}\text { Observado en las áreas de bosque y orillas de quebradas de la } \\
\text { comunidad. }\end{array}$ \\
\hline Ojoche & Brosimun alicastrum & Principalmente en las zonas de reserva \\
\hline Ceiba & Ceiba pentandra & Los ejemplares observados, se encuentran en las áreas de reserva. \\
\hline Javillos & Hura crepitans & Observado principalmente en las áreas de reserva. \\
\hline Cedro & Cedrela odorata & $\begin{array}{l}\text { Presentes en áreas abiertas, o en regeneración natural. Se puede observar } \\
\text { ejemplares aislados en las parcelas. }\end{array}$ \\
\hline Laurel & Cordia alliodora & $\begin{array}{l}\text { Se puede observar principalmente en áreas de pastos o, áreas destinadas } \\
\text { a cultivos. }\end{array}$ \\
\hline Guarumo & Cecropia sp. & $\begin{array}{l}\text { Esta es una especie bastante común en el asentamiento, se puede } \\
\text { observar tanto en las parcelas en áreas de barbecho, como en zonas en } \\
\text { regeneración y bosque secundario. }\end{array}$ \\
\hline Hule & Castilla elastica & $\begin{array}{l}\text { Fácil de observar en los bordes de los bosques y zonas en regeneración } \\
\text { natural presentes en el asentamiento. }\end{array}$ \\
\hline Balsa & Ochroma pyramidale & Principalmente en las áreas en regeneración o, en áreas en barbecho. \\
\hline
\end{tabular}

Fuente: INBio, 2011

CUADRo 7

Manifestaciones culturales en la comunidad del Futuro

\begin{tabular}{lll}
\multicolumn{1}{c}{ Organización } & \multicolumn{1}{c}{ Actividad } & \multicolumn{1}{c}{ Frecuencia } \\
Iglesia católica & Misa & Una vez a la semana \\
& Liturgia & Una vez a la semana \\
& Catequesis & - \\
Iglesia evangélica & Culto & Una vez a la semana \\
Asociación de desarrollo & Fiestas populares & Dos veces al año \\
\hline
\end{tabular}

Fuente: Elaboración propia, 2008-2011.

embalse, el cual será construido en una parcela ubicada en el asentamiento, que pertenece a Coopeornamentales, posteriormente el agua será conducida al área de casa de máquinas, cuya infraestructura será desarrollada en la zona de reserva.

\section{San José de La Tigra}

Ubicación geográfica

Se localiza en el distrito de La tigra, Cantón de san Carlos, Provincia de Alajuela (ver figura 4).

\section{Cercanía con los principales centros poblacionales de la zona}

Debido a la ubicación de esta comunidad y su accesibilidad, permite fácil a los principales centros poblacionales de la zona (ver figura 4 y cuadro 8).

\section{Cercanía con los atractivos turísticos más reconocidos}

Igualmente desde la comunidad se puede acceder a los principales sitios de interés turístico (cuadro 9) 


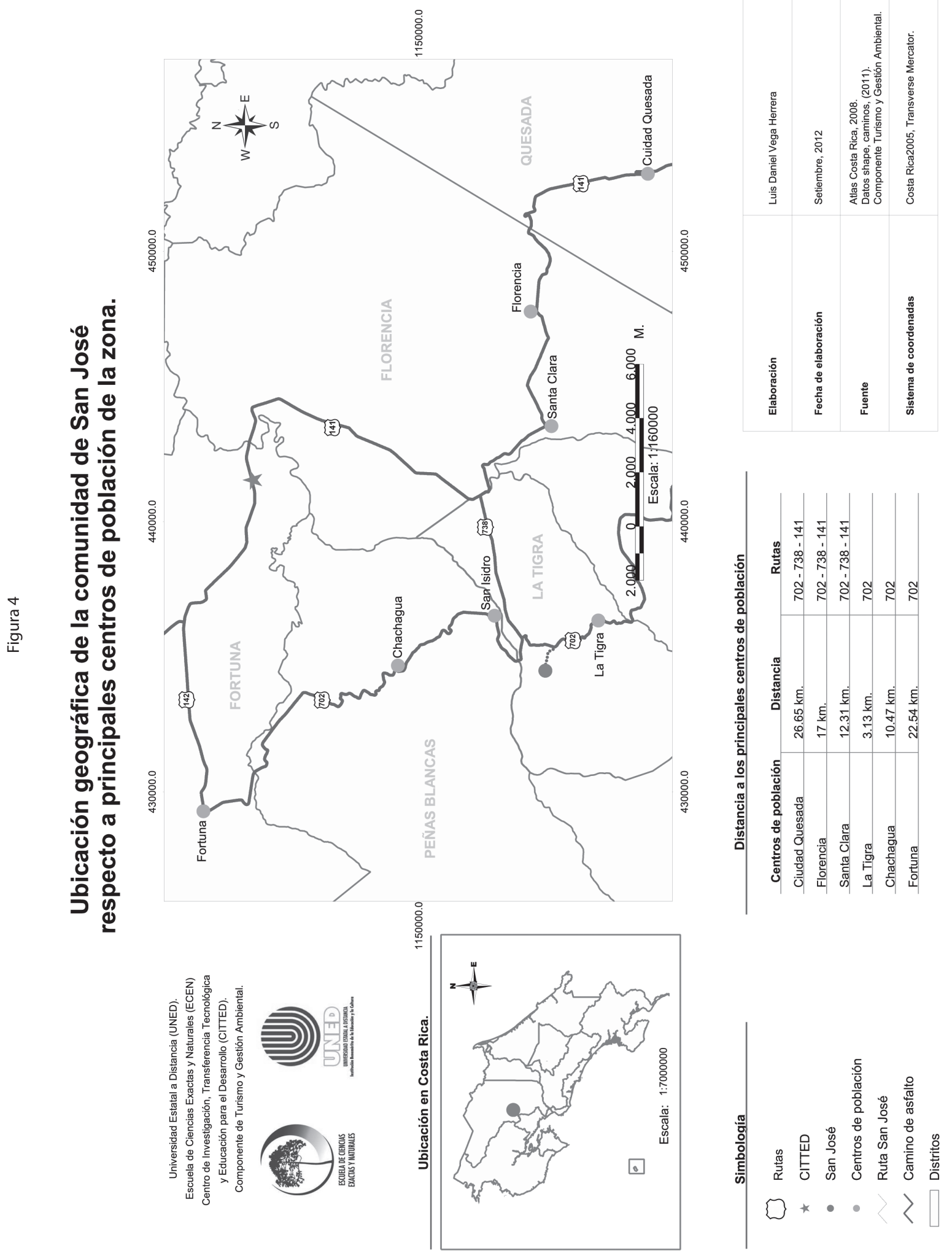


CuAdRo 8

Principales centros poblacionales

\begin{tabular}{llcc}
\multicolumn{1}{c}{ Comunidad } & \multicolumn{1}{c}{$\begin{array}{c}\text { Principales } \\
\text { poblados }\end{array}$} & $\begin{array}{c}\text { Distancia en } \mathrm{km} \\
\text { desde la comunidad }\end{array}$ & $\begin{array}{c}\text { Distancia aproximada } \\
\text { en tiempo desde la comunidad }\end{array}$ \\
San José & Ciudad Quesada & 25,48 & $45 \mathrm{~min}$. \\
de La Tigra & Florencia & 17 & $20 \mathrm{~min}$. \\
& Santa Clara & 12.33 & $15 \mathrm{~min}$. \\
& La Tigra & 3.13 & $5 \mathrm{~min}$. \\
& Chachagua & 10.48 & $20 \mathrm{~min}$. \\
& Fortuna & 22.57 & $45 \mathrm{~min}$. \\
\hline
\end{tabular}

Fuente: Elaboración propia, 2008-2011.

CUADRO 9

Distancia entre la comunidad de El Futuro y los principales atractivos turísticos de la región

\begin{tabular}{llr}
\multicolumn{1}{c}{ Comunidades } & Atractivos & Distancia en kilómetros \\
San José de La Tigra & Lago Arenal & $39.54 \mathrm{~km}$. \\
& Parque Arenal & $38.79 \mathrm{~km}$. \\
& Cavernas de Venado & $60.4 \mathrm{~km}$. \\
& Caño Negro & $137.36 \mathrm{~km}$. \\
& Estación Biológica Bosque Eterno de los Niños & $14 \mathrm{~km}$. \\
\hline
\end{tabular}

Fuente: elaboración propia basada en trabajo de campo, 2012.

Servicios de que dispone la comunidad: cantidad y ubicación

El servicio de agua potable es brindado por Cooperenacer, en general la comunidad cuenta con un buen abastecimiento de este recurso. Destaca que la comunidad tiene acceso al servicio de energía eléctrica, el cual es brindado por Coopelesca. Además hay acceso al servicio de telefonía fija, también existe disponibilidad de teléfono público. Ambos servicios son ofrecidos por el ICE. En cuanto a telefonía móvil, la comunidad cuenta con buena cobertura de este servicio.

En lo referente a la atención médica, los miembros de la comunidad deben desplazarse hasta el EBAIS de La Tigra para recibir el servicio. (Cuadros 10 y 11)

CUADRO 10

\section{Servicios presentes en la comunidad}

\begin{tabular}{lll}
\multicolumn{1}{c}{ Comunidad } & \multicolumn{1}{c}{ Servicios Básicos presentes } \\
San José de & Agua potable & Cooperenacer \\
La Tigra & Electricidad & COOPELESCA \\
& Telefonía fija & ICE \\
& Telefonía celular & ICE, Full Móvil, Tuyo Móvil, Movistar \\
& Internet & ICE, RACSA, COOPELESCA \\
& Educación preescolar y primaria. & Ministerio de Educación Pública (MEP) \\
& Salud (atención básica). & Caja Costarricense de Seguro Social (EBAIS La Tigra) \\
\hline
\end{tabular}

Fuente: Elaboración propia, 2008-2011. 
Organizaciones presentes en la comunidad

\begin{tabular}{ll}
\multicolumn{1}{c}{ Comunidad } & Organizaciones \\
San José de & Asociación de desarrollo \\
La Tigra & Cooperenacer \\
& Junta de Educación \\
& Patronato escolar \\
& Consejo Económico (iglesia Católica) \\
& Asociación las Marianas \\
& Comité de deportes \\
& Comité de Salud \\
& Grupo de Jóvenes \\
& Oficina de Crédito de FUNDECOCA, administrada por un comité de crédito de la comunidad. \\
& Organización de mujeres Tierra Fértil. \\
\hline
\end{tabular}

Fuente: Elaboración propia, 2008-2011.

\section{Acceso a la comunidad}

Esta comunidad cuenta con caminos en buen estado, la carretera principal está pavimentada hasta el centro comunal. Las principales rutas de acceso son las siguientes:

- Ruta 702 que cubre de San Ramón - La Fortuna.

- Ruta 738 que cubre Javillos - La Tigra

- Ruta 739 que cubre San Ramón - Santa Clara - San Carlos.

Iniciativas turísticas

Asociación Las Marianas: Venta de comidas criollas, turismo rural.

Atractivos presentes en la comunidad: Como atractivo principal se puede destacar la gastronomía de la región.

\section{Culturales}

Principalmente lo referente a la parte de gastronomía, esta asociación tiene una pequeña empresa que se dedica a la producción de tamales navideños, picadillo de papaya y otros platillos típicos de la zona.

\section{Necesidades de capacitación}

- Presentación de alimentos

- Serviduría de alimentos = técnicas de servicio.

- Mercadeo

- Cocina criolla costarricense (este curso lo ofrece el INA).

\section{Observaciones}

La asociación las Marianas ya han tenido experiencias con turismo, anteriormente la empresa Mapaches Tours traía grupos de Alemanes a almorzar (grupos de hasta 20 personas), la conexión se daba a través de la Asociación Conservacionista Monteverde (ACM), pero, las Marianas manifiestan que la oficina fue trasladada a otro sitio, lo cual, provocó que se perdiera el vínculo con la tour operadora.

También han trabajado con empresas como Dos Pinos, Coopelesca (cocina de turno: con tiquete), Municipalidad y Banco Popular.

Actualmente la mayor parte del producto es vendido a nacionales en la feria de La Fortuna, donde tienen un puesto. Los días de venta son los jueves y viernes. 
Para establecer el precio de sus productos se guían con los precios de los turnos, ese es su indicador. Cuentan con un menú y tienen factura.

Se dan a conocer a través de programas de televisión local como Guía Agropecuaria y el Andariego (Canal 14), también por medios como Radio San Carlos, boca a boca, turnos, la feria, Coocique. Anteriormente tenían tarjetas de negocio.

Las instalaciones necesitan mejoras, actualmente no cuentan con un área de baños adecuada, tampoco hay rotulación.

Las familias que integran la asociación también tienen parcelas, las cuales están dedicadas a la producción agrícola.

\section{San Juan de Peñas Blancas}

\section{Ubicación geográfica}

Esta comunidad está localizada en el distrito de Peñas Blancas, Cantón de San Ramón, de la provincia de Alajuela.

\section{Cercanía con los principales centros}

poblacionales de la zona

Por su ubicación se puede contar con acceso a los poblados de Chachagua, La Tigra y Santa Clara (ver figura 5 y cuadro 12).

\section{Cercanía con los atractivos turísticos} más reconocidos

Esta comunidad está localizada cerca de la ruta principal hacia fortuna (Ruta 702 que cubre de San Ramón - La Fortuna), lo cual permite desplazarse con facilidad y en poco tiempo a los diferentes sitios de interés turístico de la región (cuadro 13).

\section{Organizaciones presentes en la comunidad}

Organizacionalmente esta comunidad está integrada por un total de nueve comités que se enlistan en el cuadro 14.

Servicios de que dispone la comunidad: cantidad y ubicación.

El agua en la comunidad es abastecida por la ASADA Las Delicias de Peñas Blancas, la cual, también abastece otras comunidades vecinas. En cuanto a electricidad, el $100 \%$ de la comunidad tiene cobertura de este servicio, el cual, es proveído por Coopelesca R.L.

San Juan de Peñas Blancas cuanta con acceso a telefonía fija e internet, en cuanto a telefonía móvil, hay cobertura en toda la comunidad y el servicio es ofrecido por varias operadoras (cuadro 15).

Para recibir atención médica básica, los miembros de la comunidad deben desplazarse al EBAIS de San Isidro de Peñas Blancas, el cual se encuentra a unos cinco minutos del centro de la comunidad.

Acceso a la comunidad

Las principales ruta de acceso son:

- Ruta 702 que cubre de San Ramón - La Fortuna.

CuAdro 12

Principales centros poblacionales

\begin{tabular}{|c|c|c|c|}
\hline Comunidad & $\begin{array}{l}\text { Principales } \\
\text { poblados }\end{array}$ & $\begin{array}{c}\text { Distancia en km desde } \\
\text { la comunidad }\end{array}$ & $\begin{array}{c}\text { Distancia aproximada } \\
\text { en tiempo desde la comunidad }\end{array}$ \\
\hline \multirow{6}{*}{$\begin{array}{l}\text { San Juan de } \\
\text { Peñas Blancas }\end{array}$} & Ciudad Quesada & 25,48 & $45 \mathrm{~min}$. \\
\hline & Florencia & 17 & $20 \mathrm{~min}$. \\
\hline & Santa Clara & 12.33 & $15 \min$. \\
\hline & La Tigra & 3.13 & $5 \mathrm{~min}$. \\
\hline & Chachagua & 10.48 & $20 \mathrm{~min}$. \\
\hline & Fortuna & 22.57 & $45 \mathrm{~min}$. \\
\hline
\end{tabular}

Fuente: Elaboración propia, 2008-2011. 


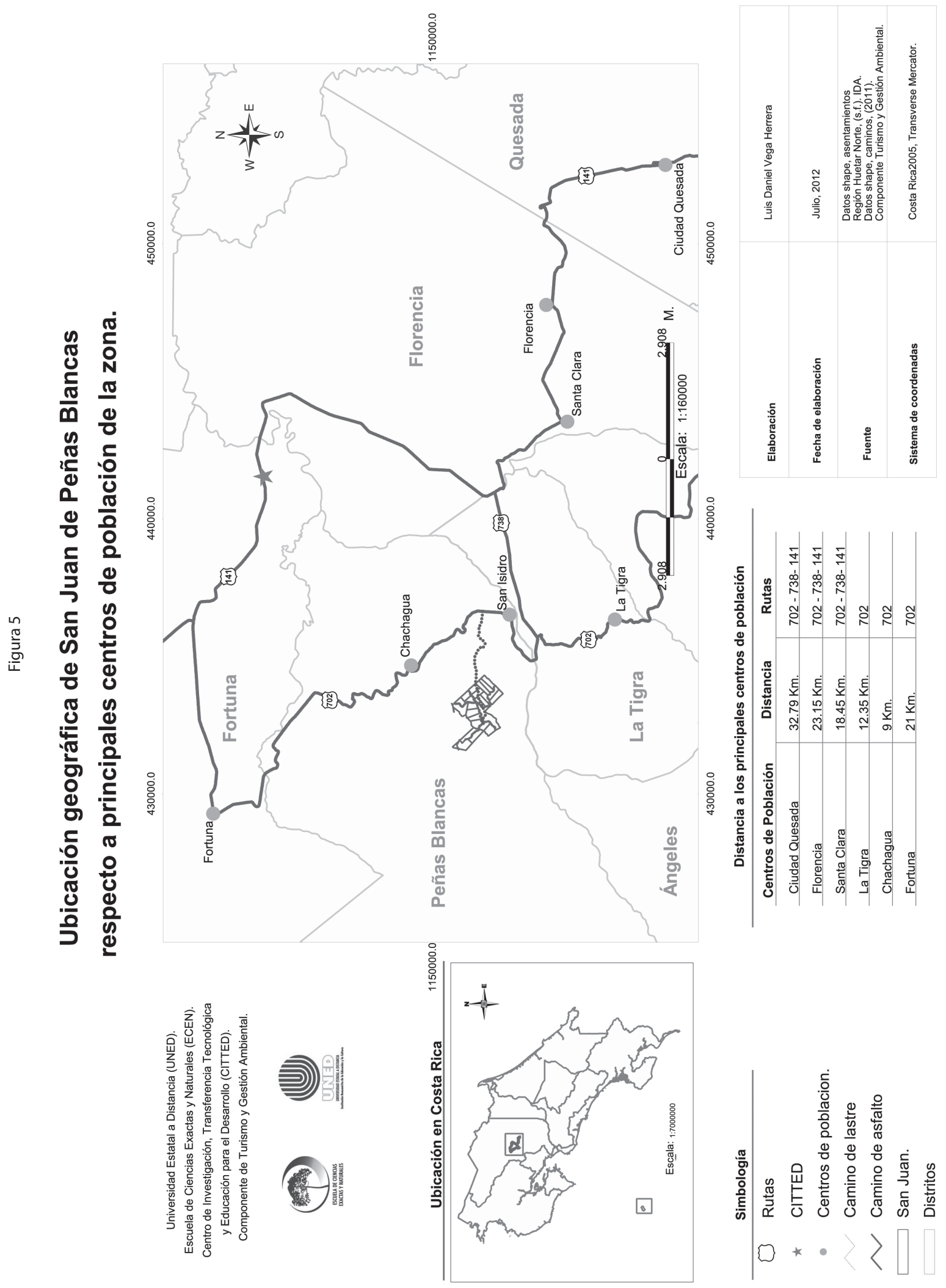




\section{CUADRO 13}

\section{Distancia entre la comunidad de San Juan de Peñas Blancas y los principales atractivos turísticos de la región}

\begin{tabular}{clr} 
Comunidades & & Distancia en kilómetros \\
San Juan de Peñas Blancas & Lago Arenal & $38 \mathrm{~km}$. \\
& Parque Arenal & $37.25 \mathrm{~km}$. \\
& Cavernas de Venado & $61.7 \mathrm{~km}$. \\
& Caño Negro & $143.5 \mathrm{~km}$. \\
& Estación Biológica Bosque Eterno de los Niños & $11 \mathrm{~km}$. \\
\hline
\end{tabular}

Fuente: elaboración propia basada en trabajo de campo, 2012.

\section{CUADRO 14}

\section{Organizaciones presentes en la comunidad}

\begin{tabular}{ll}
\multicolumn{1}{c}{ Comunidad } & \multicolumn{1}{c}{ Organizaciones } \\
$\begin{array}{l}\text { San Juan de } \\
\text { Peñas Blancas }\end{array}$ & $\begin{array}{l}\text { Asociación de desarrollo de San Juan } \\
\text { parte alta de San Isidro). }\end{array}$ \\
& Asociación de Vecinos Productores Agropecuarios San Juan de Peñas Blancas. \\
& Junta de Educación \\
& Patronato escolar \\
& Junta Administrativa Telesecundaria San Juan de Peñas Blancas. \\
& Consejo Económico (iglesia Católica) \\
& Comité de deportes \\
& Comité de caminos
\end{tabular}

Fuente: Elaboración propia, 2008-2011.

\section{Cuadro 15}

\section{Servicios presentes en la comunidad}

\begin{tabular}{lll} 
Comunidad & \multicolumn{1}{c}{ Servicios Básicos presentes } & \multicolumn{1}{c}{ Proveedor } \\
San Juan & Agua potable & ASADA las Delicias de Peñas Blancas. \\
de Peñas & Electricidad & COOPELESCA \\
Blancas & Telefonía fija & ICE \\
& Telefonía celular & ICE, Full Móvil, Tuyo Móvil, Movistar \\
& Internet & ICE. \\
& Educación primaria y secundaria. & Ministerio de Educación Pública (MEP) \\
& Salud (atención básica). & Caja Costarricense de Seguro Social (EBAIS San Isidro, Peñas Blancas). \\
\hline
\end{tabular}

Fuente: Elaboración propia, 2008-2011. 
- Ruta 738 que cubre Javillos - San Isidro

- Las vías internas son de lastre las cuales suman un total de \# km.

Iniciativas turísticas

Asociación de Vecinos Productores

Agropecuarios San Juan de Peñas Blancas

\section{Iniciativa}

Desarrollar un proyecto en turismo rural comunitario que permita complementar las actividades productivas que realizan los afiliados de la asociación de Vecinos.

\section{Atractivos presentes en el sitio}

\section{Naturales}

Esta comunidad está localizada en la parte alta del distrito de Peñas Blancas, con una elevación que va desde los 400 m.s.n.m., hasta los 800 m.s.n.m., al oeste, está limitada por el área de conservación Arenal; debido a estas características, se evidencia una amplia diversidad de flora y fauna, además de áreas de bosques ripario y tributarios de agua que alimentan el río Peñas Blancas.

\section{Culturales}

Como atractivos culturales se identificó principalmente las actividades agrícolas que desarrolla la comunidad, vida cotidiana de los pobladores.

\section{Necesidades de capacitación}

De acuerdo con la iniciativa del grupo se identificaron necesidades de capacitación en los siguientes temas:

- Diseño de senderos.

- Manejo y conducción de grupos.

- Calidad.

- Manipulación de alimentos.

- Primeros auxilios.
Necesidades de apoyo técnico

Principalmente necesitan acompañamiento técnico en temas como:

- Producción orgánica

- Manejo integrado de plagas, enfermedades en cultivos, manejo integrado del ganado vacuno.

- Producción agrícola en ambientes protegidos

- Diseño del producto turístico.

\section{Observaciones}

La universidad de Texas construyó un Centro de Investigación (Soltis) en la comunidad. A través de este Centro la comunidad ha recibido apoyo en la construcción de un aula de cómputo para el colegio.

Actualmente tienen interés en apoyar el desarrollo de actividades turísticas en la comunidad.

Comunidades diagnosticadas en el distrito de Pital de San Carlos

La zona que comprende el distrito de Pital, tiene un gran potencial turístico, este distrito cuenta con un refugio de vida silvestre mixto (Refugio Mixto Maquenque) y en el límite norte con un corredor biológico fronterizo, ambos con una biodiversidad muy rica en flora y fauna.

Instituciones presentes en la zona

En la región existe presencia de instituciones públicas y privadas que dan soporte a las comunidades en diferentes áreas, como lo son, técnicos, financieros, salud y de educación. Seguidamente se realizará una breve descripción de cada una de las áreas mencionadas.

\section{Servicios financieros}

En la zona hay presencia de diferentes instituciones u organizaciones, principalmente de carácter público, que ofertan servicios financieros suficientes para atender a los pobladores 
del distrito de Pital; algunos de los servicios que brindan son: créditos a la producción, ahorros, inversiones, tarjeta de crédito, pago de servicios de agua, luz o municipales, etc. En total se identificaron tres instituciones que brindan servicios crediticios que atienden a los pobladores de este distrito (Cuadro 16).

\section{Servicios técnicos}

Existe una cobertura regular por parte de instituciones principalmente públicas, las cuales, dan soporte técnico en diferentes áreas a las comunidades de la región (Cuadro 17).

\section{Servicios de salud}

La zona cuenta con tres Equipos Básicos Integrales de salud (EBAIS), para la atención primaria, los cuales se encuentran distribuidos en los centros poblacionales cercanos a la cabecera del distrito de Pital. Además de estos tres EBAIS, existen tres consultorios médicos ubicados en comunidades más distantes (Cuadro 18).

\section{CUADRO 16}

\section{Instituciones financieras presentes en la zona}

\begin{tabular}{|c|c|}
\hline Institución & Servicios que Ofrecen \\
\hline Banco de Costa Rica & $\begin{array}{l}\text { Pago de servicios básicos, ahorro, capitalización de inversiones, tarjeta de débito, remesas, } \\
\text { fideicomisos fondos de pensiones, otros. }\end{array}$ \\
\hline Banco Nacional & $\begin{array}{l}\text { Pago de servicios básicos, ahorro, capitalización de inversiones, tarjeta de débito, remesas, } \\
\text { fideicomisos, fondos de pensiones, otros. }\end{array}$ \\
\hline Coocique R.L. & $\begin{array}{l}\text { Pago de servicios básicos, ahorro, capitalización de inversiones, tarjeta de débito, remesas, } \\
\text { fideicomisos. }\end{array}$ \\
\hline
\end{tabular}

Fuente: SIRZEE, 2010. MAG, 2008.

\section{CUADRo 17}

\section{Instituciones de apoyo técnico presentes en la zona}

\begin{tabular}{|c|c|}
\hline Institución & Servicios que ofrecen \\
\hline Ministerio de Agricultura y Ganadería (MAG). & $\begin{array}{l}\text { Asistencia técnica en producción de plantas ornamentale } \\
\text { desarrollo de planes estratégicos empresariales y } \\
\text { asesoramiento permanente en administración. }\end{array}$ \\
\hline Instituto de Desarrollo Agrario (IDA). & $\begin{array}{l}\text { Fortalecimiento de asentamientos campesinos y ordenar } \\
\text { territorial, logrando crear en el área de influencia cinco } \\
\text { asentamientos campesinos, infraestructura comunal, titu } \\
\text { y la compra de dos fincas para grupos de productores. }\end{array}$ \\
\hline Consejo Nacional de Producción (CNP). & $\begin{array}{l}\text { Asesoramiento en plantas de procesos y comercializació } \\
\text { productos, apoyo en la legalización de la organización, d } \\
\text { de logotipo y estrategias de mercado, certificación de pla } \\
\text { de proceso, entre otros. }\end{array}$ \\
\hline Instituto Nacional de Aprendizaje (INA). & $\begin{array}{l}\text { Capacitación en administración, finanzas, contabilidad, } \\
\text { desarrollo empresarial y de proyectos, así como asesoran } \\
\text { en aspectos administrativos contables. }\end{array}$ \\
\hline $\begin{array}{l}\text { Centro de Investigación, Transferencia Tecnológica y } \\
\text { Educación para el Desarrollo (CITTED - UNED). }\end{array}$ & $\begin{array}{l}\text { Entes de Estudio superiores que realizan actividades de } \\
\text { Investigación y extensión. }\end{array}$ \\
\hline
\end{tabular}

Instituto Tecnológico de Costa Rica (ITCR).

Fuente: MAG, 2008. 


\section{CUADRO 18}

Distribución de EBAIS y consultorios médicos en el distrito de Pital de San Carlos.

\begin{tabular}{|c|c|c|c|c|}
\hline Distrito & Comunidad & EBAIS & Consultorios & Población \\
\hline \multirow[t]{5}{*}{ Pital } & Pital & EBAIS Pital 1 y 2 & & 9192 \\
\hline & Veracruz & EBAIS Veracruz & & 2876 \\
\hline & Piedra Alegre & EBAIS El Saíno & Consultorio médico & 3595 \\
\hline & Saíno & & & \\
\hline & Boca Tapada & & Consultorio médico & \\
\hline Cutris & Boca San Carlos & & Consultorio médico & \\
\hline
\end{tabular}

Fuente: SIRZEE, 2010

\section{Boca San Carlos}

\section{Ubicación geográfica}

Esta comunidad está localizada en dos distritos del cantón de San Carlos, Pital y Cutris respectivamente; esto debido que la comunidad se ha desarrollado a ambos lados del río San Carlos, el cual representa el límite entre estos dos distritos. La comunidad de Boca San Carlos está limitada al norte por el Río San Juan.

Cercanía con los principales centros poblacionales de la zona

Debido a su ubicación geográfica esta comunidad está considerable mente retirada de los principales centros poblacionales del cantón de San Carlos, el centro más cercano es el caserío de Pital, el cual se localiza a unos $46 \mathrm{~km}$ de distancia, respecto a los demás centros poblacionales guarda una distancia aproximada entre los 90 y $100 \mathrm{~km}$.

\section{Cercanía con los atractivos turísticos más reconocidos}

Igualmente boca San Carlos está considerablemente alejada de los principales sitios de interés turístico que se encuentran en la región (ver figura 6 y cuadro 19).

\section{Organizaciones presentes en la comunidad}

En la comunidad se identificaron cuatro comités entre los cuales están los siguientes:

- Asociación de desarrollo

- Junta de educación

- Patronato escolar

- Comité de acueducto

Servicios de que dispone la comunidad: cantidad y ubicación

Respecto al servicio de aguia potable, Boca San Carlos no cuenta con un sistema adecuado

CUADRO 19

Distancia entre la comunidad de Boca San Carlos y los principales atractivos turísticos de la región

\begin{tabular}{llr}
\multicolumn{1}{c}{ Comunidades } & Atractivos & Distancia en kilómetros \\
Boca San Carlos & Lago Arenal & $139.75 \mathrm{~km}$. \\
& Parque Arenal & $139 \mathrm{~km}$. \\
& Cavernas de Venado & $149 \mathrm{~km}$. \\
& Caño Negro & ND \\
\hline
\end{tabular}

Fuente: elaboración propia basada en trabajo de campo, 2012. 


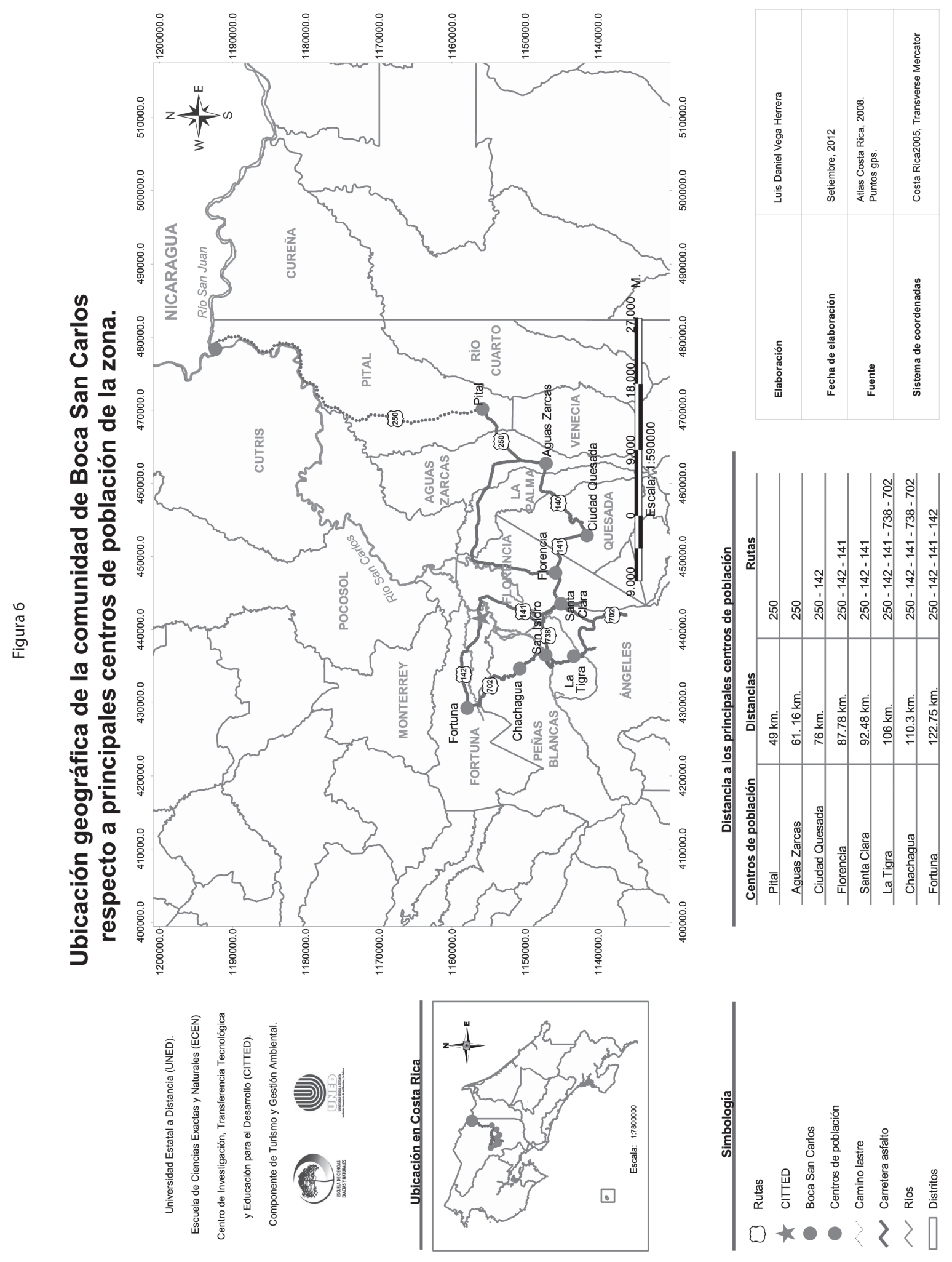


de saneamiento y distribución de agua potable. El agua se extrae de una quebrada localizada en el cerro la Chachalaca, a aproximadamente un kilómetro de la comunidad. Algunas personas cuentan con pozos perforados.

El servicio eléctrico es suministrado por Coopelesca R.L., en general cuenta con electricidad en toda la comunidad, aunque los pobladores manifiestan que este servicio se ve interrumpido a menudo.

Sobre las telecomunicaciones, solamente hay acceso a un teléfono público (a menudo falla o se encuentra averiado) y es muy limitada y localizada la cobertura para telefonía móvil.

Respecto a la salud, los miembros de la comunidad reciben atención médica básica una vez al mes, los casos de mayor importancia deben ser atendidos en el Hospital San Carlos. En caso de emergencias resulta complicado trasladar a la persona afectada hasta un centro médico, debido a la distancia y la escasa comunicación.

\section{Acceso a la comunidad}

Actualmente solo existe una ruta de acceso, que va desde el poblado de Pital, a través de las comunidades de El Saíno, Boca Tapada y posteriormente Boca San Carlos (Figura 1). Debido a problemas limítrofes entre Costa Rica y Nicaragua esta ruta está siendo reparada y, también se están abriendo nuevos cominos que amplían el acceso a la comunidad.

\section{CUADRO 20}

\section{Capacitación brindada por la ECEN a comunidades beneficiarias del Proyecto Diagnóstico del Potencial para el Desarrollo del Turismo Sostenible (2008 - 2013)}

\begin{tabular}{|c|c|c|c|}
\hline Año & Comunidades & Temas & Responsables \\
\hline \multirow[t]{4}{*}{2010} & \multirow{4}{*}{$\begin{array}{l}\text { El Futuro de La Tigra } \\
\text { Los Cerritos de La Tigra } \\
\text { San José de La Tigra } \\
\text { La Lucha de La Tigra } \\
\text { San Juan de Peñas Blancas } \\
\text { El Invu de Peñas Blancas } \\
\text { Los Ángeles de la Fortuna } \\
\text { Los Chiles }\end{array}$} & $\begin{array}{l}\text { Condición del turismo en La Fortuna de San Carlos y en } \\
\text { Asentamiento campesinos. }\end{array}$ & ECEN \\
\hline & & Diseño de senderos & ECEN \\
\hline & & Manejo y conducción de grupos & ECEN \\
\hline & & La calidad en los servicios turísticos & ECEN \\
\hline \multirow[t]{2}{*}{2011} & Boca San Carlos & $\begin{array}{l}\text { Diagnóstico de la problemática ambiental - socioeconómica y } \\
\text { sus opciones de solución en Boca San Carlos. } \\
2 \text { talleres en Agricultura Orgánica y elaboración de } \\
\text { biofertilizantes. }\end{array}$ & ECEN \\
\hline & Quebrada Grande de Pital. & $\begin{array}{l}\text { Charla de características del Turismo rural. } \\
\text { Taller de diagnóstico participativo para la elaboración de } \\
\text { propuesta en turismo rural comunitario. }\end{array}$ & ECEN \\
\hline 2012 & San Juan de Peñas Blancas & $\begin{array}{l}2 \text { Talleres de Manejo de Residuos. } \\
\text { Taller de evaluación de producto turístico. }\end{array}$ & ECEN \\
\hline \multirow[t]{2}{*}{2013} & Boca San Carlos & $\begin{array}{l}\text { Acompañamiento al desarrollo de iniciativas de turismo rural } \\
\text { comunitario. }\end{array}$ & ECEN \\
\hline & San Juan de Peñas Blancas & $\begin{array}{l}\text { Acompañamiento al desarrollo de iniciativas de turismo rural } \\
\text { comunitario en coordinación con el programa de Gestión } \\
\text { del Turismo Sostenible de la Escuela de Ciencias Sociales y } \\
\text { Humanidades por medio de capacitación no formal en temas } \\
\text { de Turismo y asistencia técnica para el diseño y mejoramiento } \\
\text { del producto turístico local. }\end{array}$ & ECEN - ECSH \\
\hline
\end{tabular}

Fuente: elaboración propia, 2013. 


\section{Conclusiones y recomendaciones}

Las actividades turísticas formales y tradicionales en la región (hotelería, restaurantes, operadores) no son en el corto plazo una opción viable desde el punto de vista técnico ni financiero para los destinatarios del proyecto; sin embargo, con un plan de acción y acompañamiento para el mejoramiento de capacidades, la UNED tiene todo el potencial para incidir en esos actores e incluso en otros funcionarios públicos y privados de la región que pueden ser partícipes de los procesos de gestión local, tal como ACM y Finca Luna Nueva Lodge; que en sus planes de responsabilidad social, han contribuido con este estudio e incidido favorablemente en los productores.

Aunque el panorama de incertidumbre de La Fortuna respecto a la financiación de proyectos turísticos y hoteleros ha permanecido constante en los últimos años; generar rutas no convencionales y proponer nuevos productos turísticos complementarios contribuirán a la diversificación de la oferta turística.

A pesar de las altas convocatorias a talleres y cursos de capacitación o asistencia en sitio, es muy mejorable aspectos de organización local para poder incrementar sus opciones de desarrollo y acceso a fondos nacionales e internacionales, bajo la figura de fundaciones, manejo compartido, gestiones comunitarias y similares.

Se tienen como limitaciones comunes la falta de conclusión de estudios formales a nivel de primaria y secundaria en casi la totalidad de informantes beneficiarios, por lo que la educación no formal en actividades de extensión y acción universitaria es fundamental; así como la coordinación interinstitucional para el incremento de relaciones universidad-sociedad-empresasentidades estatales.

A pesar de las condiciones transitables de los caminos en el área de estudio; las distancias de recorrido desfavorecen la conectividad y acceso por la dinámica de la oferta de horarios y rutas de transporte colectivo.

Las posibilidades de generación de nuevos productos turísticos deben ser complementarias y no sustitutas de la vocación y tradición agropecuaria en los asentamientos; de modo que se dé un mejor aprovechamiento y valoración de la cultura local y sus recursos agropecuarios y naturales.

La innovación y la responsabilidad social y ambiental en la generación de nuevas propuestas debe ser un referente para la participación de los beneficiarios en las actividades económicas agropecuarias y productivas, de modo que haya coherencia con las tendencias mundiales y financieras nacionales articuladas con los planes de desarrollo e investigación. Generar actividades nocturnas de bajo impacto ambiental, energías alternativas locales, transporte animal o sin vehículos con combustibles fósiles como botes o bicicletas que minimizan la huella de carbono y derrames de combustibles, la producción y venta de alimentos y bebidas con responsabilidad en el recurso agua y sin agroquímicos y el uso de especies provenientes de producción sostenible, son opciones a considerar que calarán en el sector turismo regional.

No ha sido un elemento a considerar por la responsabilidad y potestad legal del Ministerio de Ambiente y Energía sobre el recursos bosque de las reservas de asentamientos; la posibilidad de otorgar acciones de extensión ambiental y aprovechamiento sostenible de los ecosistemas fuera de las zonas productivas; lo que puede valorarse para incrementar las capacidades locales y complementar la acción institucional.

Es imperativo desarrollar acciones y estudios complementarios en la región con la debida asignación de recursos institucionales, pues las decisiones de colaboradores de turno y las posibilidades de coincidir con las agendas de cada institución, aunque denotan una gran voluntad y colaboración; dependen de factores ajenos a la planificación y orden de los recursos estatales.

Contar con facilitadores locales ha sido uno de los factores determinantes para colectar información, convocatoria a talleres y mitigar las condiciones de los agentes externos; por lo que debe ser una condición permanente en este tipo de actividades universitarias. 


\section{Agradecimientos}

A la Dirección de la Escuela de Ciencias Exactas y Naturales de la UNED en las personas de don Olman Días Sánchez y don Luis Eduardo Montero Castro por su apoyo y fortalecer con recursos y gestiones, el desempeño del personal de planta de la ECEN y del CITTED.

A las Vicerrectorías de la UNED que han apoyado muchos procesos de extensión docente e iniciativas con fondos de Regionalización, atendiendo las necesidades de la docencia en las comunidades. A la Comisión de Investigación y Extensión de la ECEN (Franklin Salas, María Elena Murillo, Martha Calderón, Carlos Quesada, Rosssy Ulate).

A los colaboradores del Refugio de Vida Silvestre Mixto Maquenque, Área de Conservación Arenal Huetar Norte (Rogelio Jiménez) y Clubes 4S (Edgar Rojas) que nos han ayudado con la organización y ejecución de talleres, convocatorias a informantes clave y en ocasiones hasta con vehículos propios para poder continuar con la tarea de fomentar emprendedurismo en la Región Huetar Norte. Por su apoyo técnico y logístico al personal del Bosque Eterno de los Niños y de Finca Luna Nueva Lodge.

A los productores de los asentamientos rurales. A los compañeros del CITTED y del Programa Gestión Turística Sostenible (José Francisco Herrera Vargas y Alex Anchía); que han proporcionado impresiones, apoyo técnico y datos complementarios de gran valor.

\section{Bibliografía}

Ángeles. D.; Retana. G.; Rodríguez. G; García.O; (2006). Com.pers. Análisis del Producto Turístico La Fortuna: ¿Cuál es la imagen que se promueve de La Fortuna a nivel nacional e internacional?. Informe del curso Impactos del Turismo en las Comunidades Receptoras. Maestría Interdisciplinaria en Gestión Ambiental y Ecoturismo, Universidad de Costa Rica (Material Inédito), San José, Costa Rica.

INBio. (2011). Especies de Costa Rica. Consultado en noviembre 18, 2011. En red: http://darnis.inbio.ac.cr/ubis/FMPro?-DB=ubipub. fp $3 \&-1$ a $y=$ Web A $11 \&-$ error $=$ norec.html\&Format $=$ default 2. htm $\&-$ SortField $=$ nombre $\% 20$ cientifico\&-Op=eq\&nueva $=\mathrm{S} \&-\mathrm{Max}=3 \&-$ Find

Ministerio de Agricultura y Ganadería (2008). Caracterización Área de Influencia agencia de servicios agropecuarios la tigra.

Ruiz. A.; (2009). Lineamientos para el desarrollo sostenible de la oferta turística del área de amortiguamiento del Parque Nacional Volcán Poás, Alajuela, Costa Rica. (Tesis). Maestría Interdisciplinaria en Gestión Ambiental y Ecoturismo. Universidad de Costa Rica, San José, Costa Rica.

Ruiz. A.; Vega. H;. (2012). Informe del componente Turismo y Gestión Ambiental. Proyecto: Diagnóstico del Potencial para el Desarrollo Turístico Sostenible en Asentamientos Campesinos del Area de influencia del CITTED (Material Inédito), La Perla. San Carlos, Costa Rica.

SIRZEE. Mapas Personalizados, Ebais Zona Norte (2010). Consultado en noviembre 17, 2011. En red: http:// www.sirzee.itcr.ac.cr/modules.php?op=modload\&na me $=$ GIS $\&$ file $=$ index 
